\title{
Characterization of deadenylation in trypanosome extracts and its inhibition by poly(A)-binding protein Pab1p
}

\author{
JOSEPH MILONE, ${ }^{1}$ JEFFREY WILUSZ, ${ }^{2}$ and VIVIAN BELLOFATTO ${ }^{1}$ \\ ${ }^{1}$ Department of Microbiology and Molecular Genetics, University of Medicine and Dentistry of New Jersey, New Jersey Medical School, \\ International Center for Public Health, Newark, New Jersey 07103, USA \\ ${ }^{2}$ Department of Microbiology, Immunology, and Pathology, Colorado State University, Fort Collins, Colorado 80523, USA
}

\begin{abstract}
The stability of mRNAs is an important point in the regulation of gene expression in eukaryotes. The mRNA turnover pathways have been identified in yeast and mammals. However, mRNA turnover pathways in trypanosomes have not been widely studied. Deadenylation is the first step in the major mRNA turnover pathways of yeast and mammals. To better understand mRNA degradation processes in these organisms, we have developed an in vitro mRNA turnover system that is functional for deadenylation. In this system, addition of poly(A) homopolymer activates the deadenylation of poly(A) tails. The trypanosomal deadenylase activity is a $3^{\prime} \rightarrow 5^{\prime}$ exonuclease specific for adenylate residues, generates $5^{\prime}$-AMP as a product, is magnesium dependent, and is inhibited by neomycin B sulfate. These characteristics suggest similarity with other eukaryotic deadenylases. Furthermore, this activity is cap independent, indicating a potential difference between the trypanosomal activity and PARN, but suggesting similarity to Ccr4p/Pop2p activities. Extracts immunodepleted of Pab1p required the addition of poly(A) competition to activate deadenylation. Trypanosomal Pab1p functions as an inhibitor of the activity under in vitro conditions. Pab1p appears to be one of several mRNA stability proteins in trypanosomal extracts.
\end{abstract}

Keywords: trypanosomes; mRNA turnover; mRNA stability; deadenylation; Pab1p; PABP

\section{INTRODUCTION}

Control of gene expression is a fundamental characteristic of all organisms. Most eukaryotes regulate gene expression at different levels, ranging from the initiation of transcription to translation. Investigations have shown that mRNA turnover is one of the major control points. Trypanosomes are parasitic protozoa that possess many deviations from the normal paradigm governing control of gene expression in eukaryotes. This group of unique organisms appears to lack significant regulation at the transcriptional level. Promoters have yet to be identified for RNA polymerase IIdependent protein-encoding genes (Vanhamme and Pays 1995; Clayton 2002). Therefore, the regulation of gene expression in these organisms appears to be largely post-transcriptional. mRNA turnover has been implicated by numerous studies to play a major role in the regulation of trypanosomal gene expression (Clayton 2002). However, thus

Reprint requests to: Vivian Bellofatto, Department of Microbiology and Molecular Genetics, UMDNJ-New Jersey Medical School, 225 Warren Street, Newark, NJ 07103, USA; e-mail: bellofat@umdnj.edu.; fax: (973) 972-3644.

Article and publication are at http://www.rnajournal.org/cgi/doi/ 10.1261/rna.5180304. far, the pathways of mRNA turnover in trypanosomes remain undefined.

Most of what is known about turnover pathways has been learned from studying these processes in yeast and mammals. Several major pathways have been identified. One major pathway consists of (1) deadenylation that removes the poly(A) tail, (2) decapping, which leads to removal of the $5^{\prime}$ cap, and (3) degradation of the body of the mRNA (Tucker and Parker 2000; Mitchell and Tollervey 2001; Wilusz et al. 2001b). A second pathway requires the exosome to degrade mRNA. In this pathway, mRNAs containing an AU-rich element (ARE) in their 3'-untranslated region (UTR) are first deadenylated followed by rapid $3^{\prime} \rightarrow 5^{\prime}$ degradation of the body of the message (Chen et al. 2001; Mukherjee et al. 2002; van Hoof and Parker 2002). All that remains following this rapid decay is a short RNA with a $5^{\prime}$ cap that is further processed by a scavenger decapping activity that functions to recycle nucleotides (Nuss et al. 1975; Wang and Kiledjian 2001).

Several mRNA decay proteins have been described in trypanosomes. The full 10-subunit exosome is conserved between trypanosomes and other eukaryotes (Estevez et al. 2001, 2003; Butler 2002). ARE-mediated turnover has been demonstrated in vivo in two trypanosome species (Drozdz 
and Clayton 1999; Di Noia et al. 2000; Quijada et al. 2002). In addition, the exosome-mediated ARE stimulated turnover pathway can be faithfully reproduced in vitro in trypanosome extracts (Milone et al. 2002). Two decapping activities have also been identified and characterized in trypanosome extracts. These extracts possess a Dcp1/Dcp2plike decapping activity that functions on long RNAs to generate $\mathrm{m}^{7} \mathrm{GDP}$, and a scavenger DcpSp-like activity that acts only on short RNAs to produce $\mathrm{m}^{7} \mathrm{GMP}$ (Milone et al. 2002). Interestingly, the potentially rate-limiting step of deadenylation, likely the initiating component of all pathways, has yet to be defined in trypanosomes.

Several eukaryotic deadenylases have been reported in the literature. Poly(A) ribonuclease (PARN) was first identified in mammals, and later in Xenopus (Astrom et al. 1992; Korner and Wahle 1997; Korner et al. 1998). PARN is an RNase D nuclease family member that functions in a capdependent manner to deadenylate mRNA (Dehlin et al. 2000; Gao et al. 2000). A PARN homolog has not been identified in yeast (Mitchell and Tollervey 2001). Pan2p, another RNase D-like nuclease family member, was identified in yeast. This enzyme is thought to function in nuclear RNA processing, and has been shown to be dependent on poly(A)-binding protein 1 (Pablp; Brown et al. 1996; Brown and Sachs 1998). Deletion of PAN2 has a minor effect on deadenylation (Brown et al. 1996). Finally, the yeast Ccr4/Pop2p protein complex $(>1 \mathrm{mDa})$ has been reported as the major cytoplasmic deadenylase (Daugeron et al. 2001; Tucker et al. 2001, 2002; Chen et al. 2002). The independent deletion of CCR4 and POP2 resulted in a slowgrowth phenotype and a reduction in mRNA decay rates. Deletion of both CCR4 and PAN2 caused mRNAs with long poly(A) tails to accumulate, suggesting that these are the major deadenylases in yeast (Tucker et al. 2001). Ccr4p is a magnesium-dependent nuclease, whereas Pop2p is a RNase D nuclease family member (Dlakic 2000; Daugeron et al. 2001). Intriguingly, the trypanosome database contains homologs for PARN, Ccr4p, and Pop2p.

In vitro mRNA turnover systems functional for deadenylation activity have been developed in mammalian and yeast extracts (Ford et al. 1999; Wang et al. 1999; Wilusz et al. 2001a; Lai et al. 2003). In some of these systems, poly(A) homopolymer competitor is added to the extract to activate deadenylation of mRNA, possibly by sequestering poly(A)binding proteins from the poly(A) tail. It has long been known that poly(A)-binding proteins stabilize mRNA (Ross 1995; Ford et al. 1997). Cap-tail interactions between Pab1p and cap-binding proteins circularize the RNA, promote translation initiation, and prevent nucleases from degrading the transcript (Wells et al. 1998; Wilusz et al. 2001b). Pablp coats the poly(A) tail and protects mRNA from degradation in mammalian, Xenopus, and yeast extracts. Pablp is an essential gene in yeast, but a deletion mutant can be examined by using a suppressor mutation in a ribosomal subunit gene. Deletion of Pablp in yeast leads to a phenotype where
mRNAs are decapped independent of deadenylation, and mRNA deadenylation rates are reduced (Caponigro and Parker 1995). As a result of these studies, it is possible to conclude that Pablp plays a role in mRNA turnover, but this role is not clearly defined.

As a first step in elucidating the trypanosomal deadenylases, we have identified a deadenylation activity in cytoplasmic extracts. Previously, we utilized this system to demonstrate that these extracts contain other known turnover activities, such as decapping, scavenger decapping, and ARE-specific $3^{\prime} \rightarrow 5^{\prime}$ exonucleolytic decay (Milone et al. 2002). In this study, we report the characterization of a trypanosomal deadenylation activity in two different trypanosomatid species, Leptomonas seymouri and Trypanosoma brucei. Furthermore, we investigated the interplay among different proteins that regulate mRNA stability and demonstrate an inhibitory role for Pablp in preventing deadenylation in trypanosomes.

\section{RESULTS}

\section{Identification and characterization of deadenylation activities in two trypanosome species}

We have previously demonstrated the presence of two decapping activities and an AU-rich element-regulated $3^{\prime} \rightarrow 5^{\prime}$ exonuclease activity in L. seymouri extracts (Milone et al. 2002). The existence of these activities prompted us to determine whether our extracts also contained a deadenylase activity. We tested for this activity by using small artificial mRNAs. The RNA substrates used were labeled internally with $\left[\alpha-{ }^{32} \mathrm{P}\right] \mathrm{UTP}$ and possess a $5^{\prime} \mathrm{m}^{7} \mathrm{G}$ cap and a 60 nucleotide (nt) long poly(A) tail. Previous deadenylation assays in mammalian and yeast extracts required the addition of excess poly(A) homopolymer to the reaction. First, we tested whether the addition of poly (A) competitor could activate deadenylation in the $L$. seymouri cytoplasmic extracts. Figure $1 \mathrm{~A}$ shows a titration of increasing amounts of either poly(A) or poly(C). The addition of poly(A) homopolymer specifically resulted in the change in substrate size from the polyadenylated form of the RNA (A60) to the deadenylated form of the RNA (A0). No significant change in size of the RNA substrate was observed by incubation of the RNA substrate in a reaction without poly(A) homopolymer or in the presence of poly $(\mathrm{C})$ homopolymer. We next determined the biochemical nature of the nuclease activity. Figure $1 \mathrm{~B}$ shows a titration from $\sim 48 \mu \mathrm{g}$ to $0 \mu \mathrm{g}$ of protein extract in the presence of excess poly $(\mathrm{A})$ homopolymer and internally radiolabeled polyadenylated RNA. Reducing the amount of extract, and thus the amount of nuclease, in the deadenylation reaction caused the accumulation of RNAs with differing poly(A) tail lengths. The increase in the amount of these decay intermediates under these conditions suggest an enzyme-limiting situation and are indicative of a 

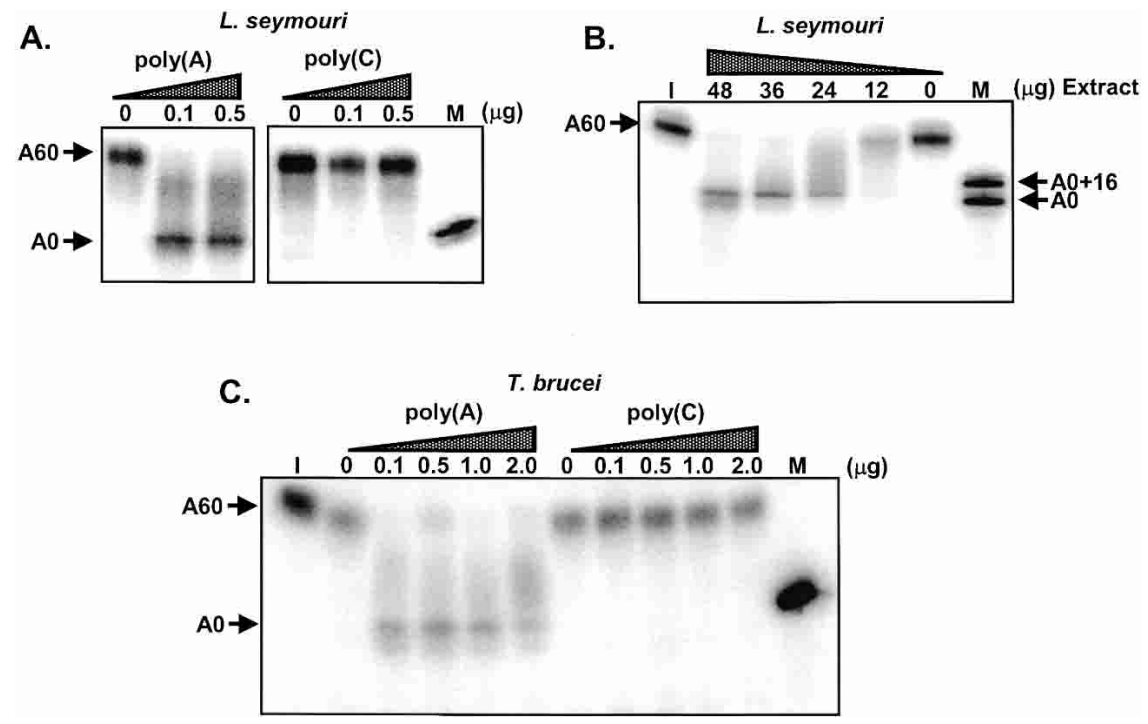

FIGURE 1. Addition of poly(A) homopolymer to trypanosomal cytoplasmic extracts activates a distributive nuclease activity. (A) Internally radiolabeled MCS A60 RNA (124 nt) substrate was incubated for $30 \mathrm{~min}$ in L. seymouri cytoplasmic extract. (B) Internally radiolabeled SLMCS ERA A60 RNA (209 nt) was incubated with decreasing amounts of L. seymouri extracts for $60 \mathrm{~min}$ as indicated. A total of $500 \mathrm{ng}$ poly(A) homopolymer was added to each reaction. (C) Internally radiolabeled Gem A60 RNA (125 nt) was incubated for $60 \mathrm{~min}$ in T. brucei cytoplasmic extract. Increasing amounts of poly $(A)$ or poly $(C)$ were added to the reactions in $A$ and $B$ as indicated. Reaction products were analyzed on a $7-\mathrm{M}$ urea $5 \%$ polyacrylamide gel following phenol extraction and ethanol precipitation. The A60 arrow indicates the input RNA substrate and the A0 arrow indicates the deadenylated form of the RNA substrate; MCS A0 (64 nt), SL-MCS ERA A0 (149 nt), and Gem A0 (65 nt), respectively, in $A, B$, and $C$. The lanes marked $I$ indicate the input RNA. The RNA A0 marker is shown in lanes marked $M$. An additional RNA marker (165 nt) was added to lane $M$ in $B$.

distributive activity. The distributive nature of the nuclease is further supported by the additional observation that an excess amount of poly(A) homopolymer in the reaction shows a decay pattern similar to that observed in Figure 1B.

In addition to L. seymouri, we prepared extracts from $T$. bruce $i$ and assayed them for deadenylation activities. Figure $1 \mathrm{C}$ shows titrations performed with $\operatorname{poly}(\mathrm{A})$ or $\operatorname{poly}(\mathrm{C})$ homopolymer using the T. brucei extracts. As observed for the $L$. seymouri extracts, the T. brucei extracts exhibited a poly(A)-activated nuclease that resulted in a size change from the polyadenylated form (A60) to the deadenylated form (A0). The deadenylase in the T. brucei extract is acting in a distributive fashion, similar to the L. seymouri extracts, as addition of excess amounts of poly(A) homopolymer (2 $\mu \mathrm{g})$ to the reaction cause an accumulation of different-sized decay intermediates. The decay intermediates are similar to the ones observed in the L. seymouri reactions in Figure 1B.

To determine the poly(A) specificity and directionality of the trypanosomal deadenylation activities, we used two additional substrates. Figure 2A shows $L$. seymouri extract incubated with an RNA substrate containing a 60 -nt poly(A) tail and with an RNA substrate containing a $60-n t$ poly(A) tail blocked at its $3^{\prime}$ end by 20 additional nonadenylated nucleotides. The left panel shows both RNAs incubated for a 30-min time course with L. seymouri extracts. The un- blocked RNA was completely deadenylated by $30 \mathrm{~min}$, whereas the blocked RNA remained fully adenylated after 30 min. The right panel shows the same experiment using $T$. brucei extracts. Again, the unblocked RNA was deadenylated and the blocked RNA remained polyadenylated. These results demonstrate that the nuclease activity in both of the trypanosome extracts are occurring in a $3^{\prime} \rightarrow 5^{\prime}$ direction. The direction of decay is supported by an additional experiment using cap-labeled polyadenylated RNA substrate in L. seymouri extracts (Fig. 4A, below, right panel). The decay of cap-labeled RNA produces the same decay pattern as internally labeled RNA. Finally, a tract of nine cytosine residues was placed in the middle of the poly(A) tail to interrupt the poly(A) tract and examine specificity of the deadenylase-like activity. Figure 2, B and $\mathrm{C}$, show time courses with the interrupted poly(A) tail in each trypanosome extract. Figure 2B shows the decay kinetics in L. seymouri extracts in a 60-min time course using either the noninterrupted or interrupted RNA substrates. A deadenylation pause is detected by $30-60 \mathrm{~min}$ in the reaction containing the substrate with the interrupted poly(A) tail. This pause appeared approximately halfway between the A60 and A0 markers and is consistent with the location of the nine-cytosine residue interruption in the poly(A) tail. A pause was not observed in the time course performed in parallel using an RNA with a noninterrupted poly(A) tail. A graphical representation of the data is shown below Figure 2B. The data are represented as distance of migration of RNA products relative to the location of the RNA A0 marker. The presence of the poly $(\mathrm{C})$ tract imbedded in the middle of the poly(A) tail caused a pause in deadenylation that is midway in distance $(\sim 12.5 \mathrm{~mm})$ between the polyadenylated $(\sim 25$ $\mathrm{mm})$ and deadenylated forms $(\sim 0 \mathrm{~mm})$ of the RNA. The $T$. brucei extracts functioned similarly to the $L$. seymouri extracts. Figure $2 \mathrm{C}$ shows the reaction products from the incubation of an uninterrupted and poly $(\mathrm{C})$ tract-interrupted RNA substrate with $T$. brucei extracts. The graph below Figure $2 \mathrm{C}$ shows the data in a graphical format. As observed for the L. seymouri reactions, the unblocked RNA deadenylated unimpeded, while the interrupted RNA substrate paused to form a decay intermediate approximately half the distance $(\sim 15 \mathrm{~mm})$ between the polyadenylated $(\sim 28 \mathrm{~mm})$ and deadenylated $(\sim 0 \mathrm{~mm})$ RNA. Therefore, we conclude that both T. brucei and L. seymouri extracts contain a $3^{\prime} \rightarrow 5^{\prime}$ adenylate-specific nuclease that is activated by the addition 

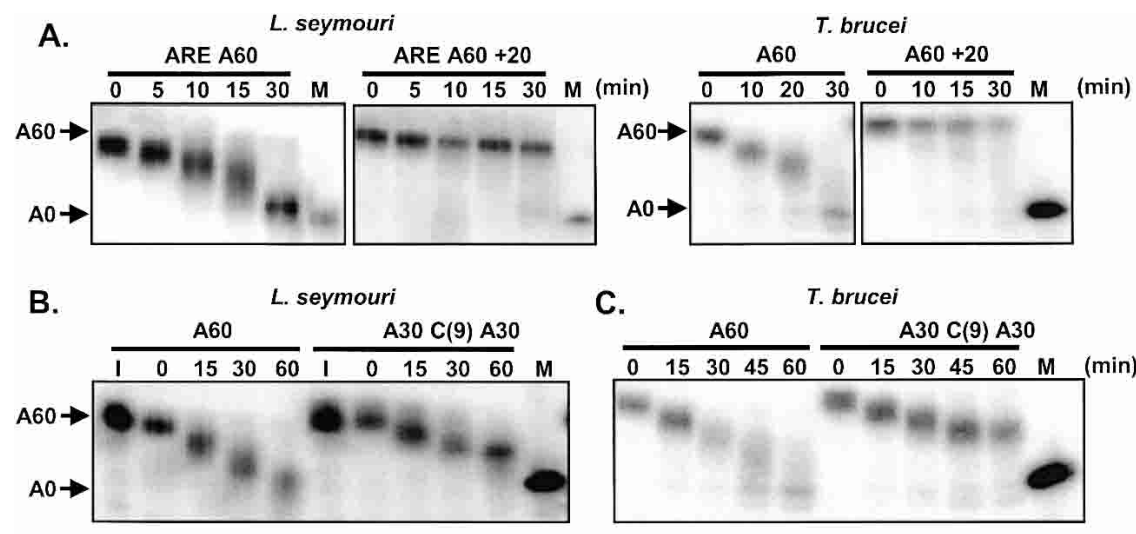

C.
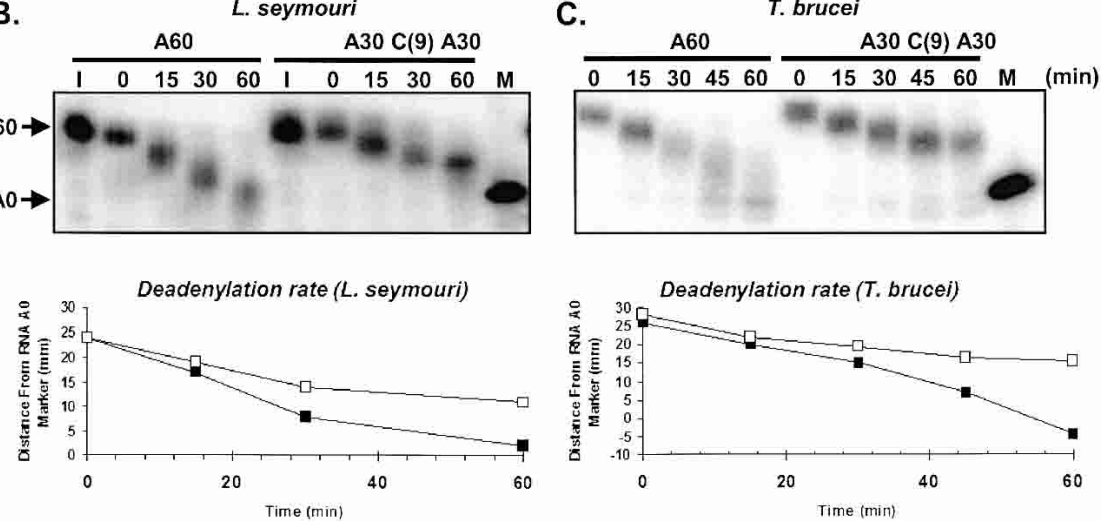

FIGURE 2. Poly(A)-activated nuclease activity is a $3^{\prime} \rightarrow 5^{\prime}$ deadenylase with specificity for adenylate residues. ( $A$, left panel) Reaction products generated in a time-course incubation of two different internally radiolabeled RNA substrates in L. seymouri extracts. The SL-MCS ARE A60 (209 nt) and SL-MCS ARE A60+20 (229 nt) substrates consist of plasmid polylinker sequence followed by a 60 -nt poly(A) tail or a 60 -nt poly(A) tail, followed by 20 additional non-poly(A) nucleotide at the $3^{\prime}$ end. (A, right panel) A similar experiment, except that Gem A60 (125 nt) and Gem A60+20 (145 nt) RNAs were incubated with T. brucei cytoplasmic extracts. $(B, C)$ Parallel time courses were performed using $L$. seymouri or T. brucei extracts with RNA substrates possessing a $60-n t$ poly $(A)$ tail or a poly(A) tail interrupted by a 9-nt poly (C) tract. SL-MCS A60 (169 nt) and SL-MCS A30 C(9) A30 (178 nt) was used with L. seymouri extract, and Gem A60 (125 nt) and Gem A30 C(9) A30 (134 nt) was used with T. brucei extract. The migration of decay intermediates after incubation are shown. Below each data set, these data are represented graphically as the distance of migration of the RNA substrate in reference to the RNA A0 marker. The graphs were generated by a continuity plot analysis of each lane, and the peak of the signal intensity was set as the point that represented distance of migration.

(ם) Uninterrupted RNA substrate decay; ( $\square$ ) decay of the interrupted poly(A) tail RNA substrate. All reaction products were separated using 7-M urea 5\% polyacrylamide gels following phenol extraction and ethanol precipitation. The A60 arrow indicates the input RNA with a poly(A) tail of $60 \mathrm{nt}$, and the $\mathrm{A} 0$ arrow indicates the deadenylated form of the RNA substrate. The lanes marked $I$ indicate the input RNA. The SL-MCS ARE A0 (149 nt), SL-MCS A0 (109 nt), and Gem A0 RNA A0 (65 nt) markers were resolved in lanes marked $M(A-C)$.

of poly(A) homopolymer. This activity is a trypanosomal deadenylase.

\section{The trypanosomal deadenylase activities possess characteristics similar to other known deadenylase activities}

It has been reported that PARN is inhibited by neomycin-B sulfate (Ren et al. 2002). To determine which of the known deadenylase activities might correspond to the trypanosomal activity identified above, we treated the trypanosomal extracts with an increasing concentration of neomycin $\mathrm{B}$ sulfate. Similarly treated HeLa cell extracts were used as a control. Figure 3A shows neomycin-B sulfate titrations for both $L$. seymouri and T. brucei cytoplasmic extracts (Fig. 3A, left panel). Inhibition of the L. seymouri activity begins at $100 \mu \mathrm{M}$ neomycin-B sulfate. The activity in the HeLa extract behaved in a similar pattern to the L. seymouri activity and was partially inhibited at a $100 \mu \mathrm{M}$ concentration. However, the T. brucei extracts were not inhibited at a neomycin-B sulfate concentration of $100 \mu \mathrm{M}$. All three extracts were completely inhibited at a concentration of $1 \mathrm{mM}$ neomycin-B sulfate. We conclude that the trypanosomal activities are inhibited at relatively similar levels of neomycin-B sulfate as other known deadenylases. Minor differences in inhibitory concentration may not be informative because of differences between extracts.

Because most deadenylases are $\mathrm{Mg}^{2+}$ dependent enzymes (Dlakic 2000; Daugeron et al. 2001; Zuo and Deutscher 2001), we tested whether the trypanosomal deadenylase also requires a divalent cation. A total of $10 \mathrm{mM}$ EDTA was added to deadenylation reactions using either trypanosomal extract, and reaction products were analyzed after 30 min. In both cases, EDTA blocked deadenylation of the RNA substrate (Fig. 3B). Reactions were also performed without the addition of magnesium to extracts. These reactions resulted in a greatly diminished deadenylation activity (data not shown). Therefore, we conclude that the trypanosomal deadenylase activity requires divalent cations, just as other known deadenylases.

The product of known deadenylase activities is $5^{\prime}$-AMP. We tested our activities to determine the product of the trypanosomal deadenylation reactions. Figure 3C shows one-dimensional TLC analysis of the deadenylation reaction products of the RNA substrate labeled at the poly(A) tail with $\left[\alpha-{ }^{32} \mathrm{P}\right]$ ATP (Martinez et al. 2001). The radioactive product of the deadenylation reaction comigrated with $5^{\prime}$ AMP in the assay. A potential $3^{\prime}$-AMP product would have migrated lower than $5^{\prime}$-AMP using the one-dimensional TLC assay. These data show that the trypanosome nuclease activity produces the same product as other known deadenylases. Ultimately, these collective data shown in Figures 1-3 provide evidence that the trypanosome nuclease activity possesses many of the properties of known deadenylases. 
A.
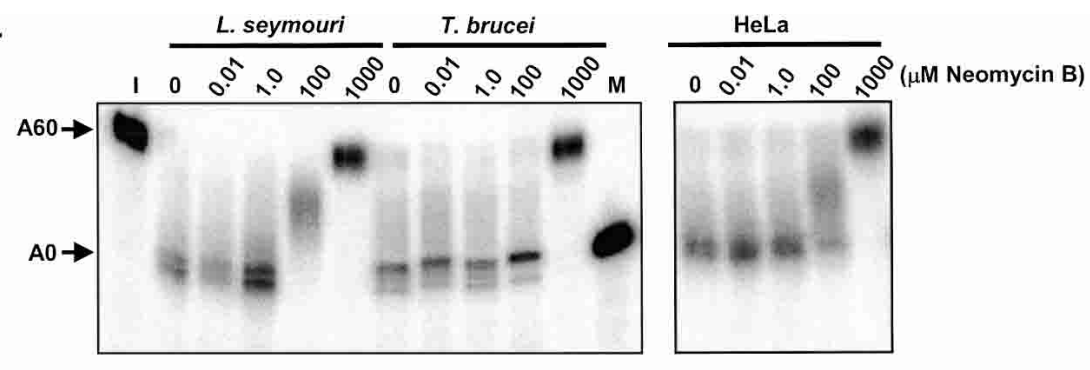

B.

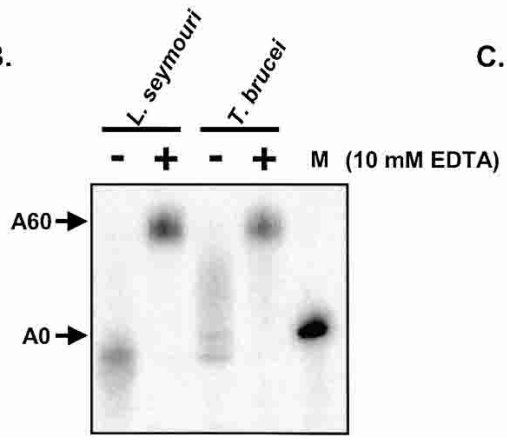

c.

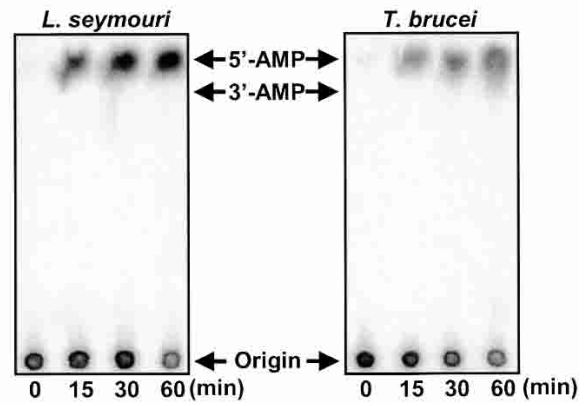

FIGURE 3. The trypanosomal deadenylation activity has characteristics similar to other known deadenylases. (A) Parallel titrations of neomycin B sulfate were performed with L. seymouri, T. brucei, and HeLa cell extracts. Deadenylation activity was assessed as described above. $(B)$ The divalent cation requirement of the trypanosomal deadenylase activity was determined by inclusion of $10 \mathrm{mM}$ EDTA in the reaction. Reaction products were analyzed by separation on 7-M urea $5 \%$ polyacrylamide gels following phenol extraction and ethanol precipitation. Arrows indicate the adenylated substrate (A60) and the deadenylated substrate (A0). Input RNA is in the lane labeled $I$. The RNA A0 marker is in the lane labeled $M$. $(C)$ One-dimensional TLC analysis of the deadenylation reaction products. RNAs radiolabeled at the poly(A) tail were incubated in trypanosomal extracts for $60 \mathrm{~min}$. The reaction products were phenol-chloroform extracted and resolved using PEI-cellulose TLC plates. The positions of UV-shadowed markers corresponding to $5^{\prime}$-AMP and $3^{\prime}$-AMP are indicated.

The trypanosomal deadenylase activity is cap independent and not stimulated by the presence of an AU-rich element

The mammalian deadenylase, PARN, interacts with the $5^{\prime}$ cap (Gao et al. 2000). Accordingly, processive deadenylation acting in mammalian extracts is cap dependent. We tested whether the $5^{\prime} \mathrm{m}^{7} \mathrm{G}$ cap is a requirement for trypanosomal deadenylases to degrade mRNA. Figure 4A (left panel) shows a time course of uncapped ( 5 ' triphosphate containing) internally labeled RNA incubated in L. seymouri extracts. The RNA was completely deadenylated by $30 \mathrm{~min}$, exhibiting kinetics similar to $\mathrm{m}^{7} \mathrm{G}$-capped RNAs (radiolabeled at the $\gamma$ Phosphate of the cap structure; Fig. 4A, right panel). The deadenylation activity in the T. brucei extracts was also found to be cap independent (Fig. 4B). $\mathrm{m}^{7} \mathrm{G}-$ capped and uncapped RNAs were incubated in T. brucei extracts for the times indicated. In both cases, the RNAs were deadenylated by $30 \mathrm{~min}$. These results suggest a similarity between the trypanosomal deadenylase activity and that of yeast, which is cap independent in vitro (Wilusz et al. 2001a).

We have previously shown that a 34-nt ARE sequence from the $3^{\prime}$ UTR of TNF- $\alpha$ functions to destabilize RNAs lacking a poly(A) tail in L. seymouri cytoplasmic extracts (Milone et al. 2002). This sequence was previously reported to slightly enhance the rate of deadenylation of RNAs in mammalian extracts (Ford et al. 1999). Therefore, we determined the deadenylation rate in trypanosome extracts of RNAs that possess a TNF- $\alpha$ ARE sequence. Figure 4C shows time courses containing an RNA with the ARE sequence and an RNA possessing the reverse ARE sequence (ERA). To the right of Figure $4 \mathrm{C}$ is a graphical representation of the data. Similar deadenylation kinetics were observed between the two substrates. We conclude that removal of a 60-nt poly(A) tail is not regulated by this element in our trypanosomal extracts.

\section{PAB1p is an inhibitor of deadenylation activity}

Pablp is a ubiquitous cytoplasmic RNA-binding protein in eukaryotes that may play a major role in the regulation of mRNA stability and translation initiation (Wilusz et al. 2001b). Studies on mammalian cells and yeast indicate that Pablp may function as a deadenylase inhibitor (Wilusz et al. 2001a). As a first step in identifying the interplay among different proteins that regulate mRNA turnover in trypanosomes, we sought to determine whether Pablp functions as a deadenylase inhibitor in trypanosome extracts. As L. seymouri and Leishmania major are closely related trypanosomes, we used an available anti-L. major Pab1p (LmPab1p) antibody for immunodepletion studies (Bates et al. 2000). Figure 5A shows Western analysis using the $L m P a b 1 p$ polyclonal antisera. The antisera detected the purified recombinant His-tagged LmPablp, as well as a similar-sized band in L. seymouri cytoplasmic extracts. We conclude that the $L$. major antiserum was able to cross-react and detect Pablp in L. seymouri extracts.

We next used the anti-LmPablp antisera to specifically deplete a $L$. seymouri extract of Pablp. Figure 5B shows Western analysis of the Pablp antisera-depleted fractions of the L. seymouri extract. Four consecutive rounds of immunodepletion were required to remove Pablp from $L$. seymouri extracts (Fig. 5B, left panel). In control experiments, parallel immunodepletions using rabbit normal sera did not significantly affect Pab1p levels in the extract (Fig. 5B, right panel). Figure $5 \mathrm{C}$ shows functional deadenylase assays utilizing the supernatants from the fourth-round immunodepletions. Surprisingly, deadenylation of polyadenylated 

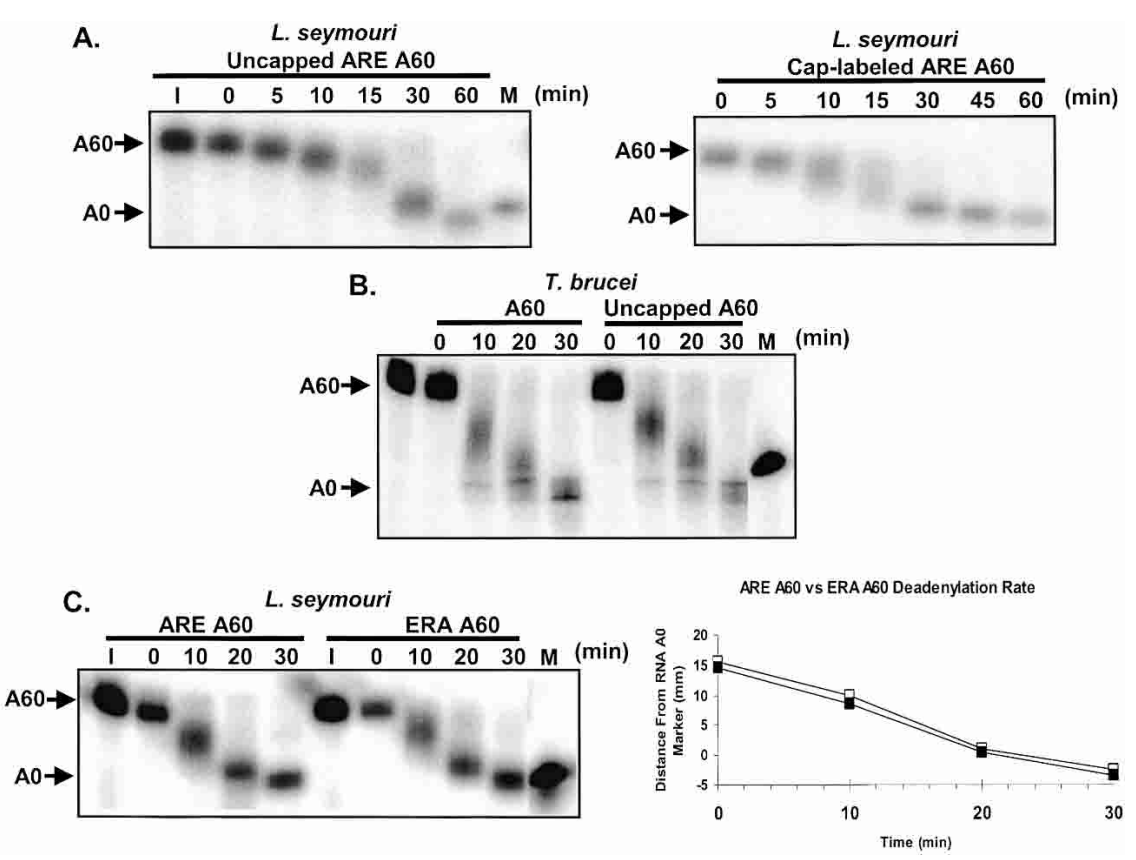

FIGURE 4. The trypanosomal deadenylase activities are cap independent and unaffected by AU-rich elements in vitro. (A, left panel) Internally radiolabeled SL-MCS ARE A60 (209 nt) RNA possessing a triphosphate cap incubated in L. seymouri cytoplasmic extracts for the indicated times. (Right panel) A parallel time course in L. seymouri extracts using $\left[\gamma^{-}{ }^{32} \mathrm{P}\right]-7-$ methyl-guanosine cap-labeled SL-MCS ARE A60 RNA (209 nt). (B) Internally radiolabeled polyadenylated Gem A60 RNA (125 nt) containing either a $\mathrm{m}^{7} \mathrm{G}$ cap or a $5^{\prime}$ triphosphate end were incubated in T. brucei extracts. (C) Internally labeled RNAs, SL-MCS ARE A60 (209 nt) and SL-MCS ERA A60 (209 nt), containing a 60-nt poly(A) tail, and either an ARE element or the reverse sequence (ERA) were incubated in L. seymouri extracts. Adjacent to the gel image is a graphical representation of the data as described in Figure 2. ( $\square$ ) Decay of the ARE containing RNA; ( $)$ Decay of the ERA containing RNA. Reaction products were separated using $7-\mathrm{M}$ urea $5 \%$ polyacrylamide denaturing gels following phenol extraction and ethanol precipitation. The arrows indicate the adenylated form (A60) and deadenylated form (A0) of the RNA substrate. The lanes labeled $I$ are input RNA. The lanes labeled $M$ are SL-MCS ARE A0 RNA (149 nt) and Gem A0 (65 nt).

RNA substrate still required the addition of poly(A) homopolymer following removal of Pablp. Therefore, the deadenylation activity remained inhibited in the Pab1-depleted extracts. These results suggest that Pablp may not be the sole inhibitor of deadenylase activity in trypanosomes.

To further explore the inhibitory nature of Pablp, we depleted a L. seymouri extract of all deadenylase inhibitors by incubation with poly(A) Sepharose. Figure 6A shows that poly(A) Sepharose batch treatment of the extract specifically removed the requirement of poly(A) homopolymer added in trans to stimulate deadenylation. As a control, the Protein G Sepharose batch-treated extract maintained its requirement for the addition of poly $(\mathrm{A})$ homopolymer. We next added purified His-tagged $L m P a b 1 p$ or BSA to the poly(A) Sepharose-depleted extracts to restore the inhibition of deadenylation (Fig. 6B). Addition of LmPablp, but not BSA, was sufficient to block the deadenylase activity. Therefore, we conclude that Pablp can function independently as an inhibitor in vitro of deadenylation in trypanosomes.

\section{DISCUSSION}

We have described the development of a trypanosome in vitro mRNA turnover system that is functional for many of the enzymatic steps in the major turnover pathways of mammals and yeast. This trypanosomal activity is specific for adenylate residues and possesses many of the hallmarks of other characterized deadenylases, namely, sensitivity to neomycin-B sulfate, divalent cation dependence, and production of $5^{\prime}$-AMP from degradation of the poly(A) tail. Ultimately, this system will allow the dissection of not only the fundamental parasite pathways for mRNA degradation, but provide an important tool that may lead to the discovery of novel proteins involved in differential gene expression.

One of the main goals of developing this system is to determine the protein(s) responsible for deadenylation in trypanosomes. In this respect, discovery of the trypanosomal deadenylation activity has provided an opportunity for comparison with existing deadenylase activities in other eukaryotes. The trypanosomal activity exhibits similarity to mammalian PARN in its sensitivity to neomycin-B sulfate, but differs in the cap-dependency requirement for the activity. Processive deadenylation by PARN proteins in both mammalian and Xenopus are cap-dependent, whereas the trypanosome activity is cap independent. Another difference is in sequence specificity as mammalian PARN activity is stimulated to some degree by ARE sequences, whereas we have been unable to show an ARE-dependent stimulation of the trypanosome activity. This is in contrast to our findings that ARE sequences stimulate degradation of nonpolyadenylated RNA in trypanosome extracts (Milone et al. 2002). Possible reasons for a lack of observed sequence regulation could be the length of the poly(A) tail and the use of a heterologous ARE sequence in the trypanosome assays. In mammalian extracts, poly(A) tails longer than 60 adenylate residues are required to observe a small stimulatory effect of the ARE in modifying deadenylation rates. It is possible that longer poly $(\mathrm{A})$ tails may be required to observe a stimulatory effect in trypanosome extracts.

The cap-independent characteristic of the trypanosomal activity is similar to the yeast Ccr4p/Pop2p deadenylase. Homologs to CCR4 and POP2 are present in the T. brucei database; thus, it is possible that one of these enzymes may account for the observed trypanosome activity. Alterna- 


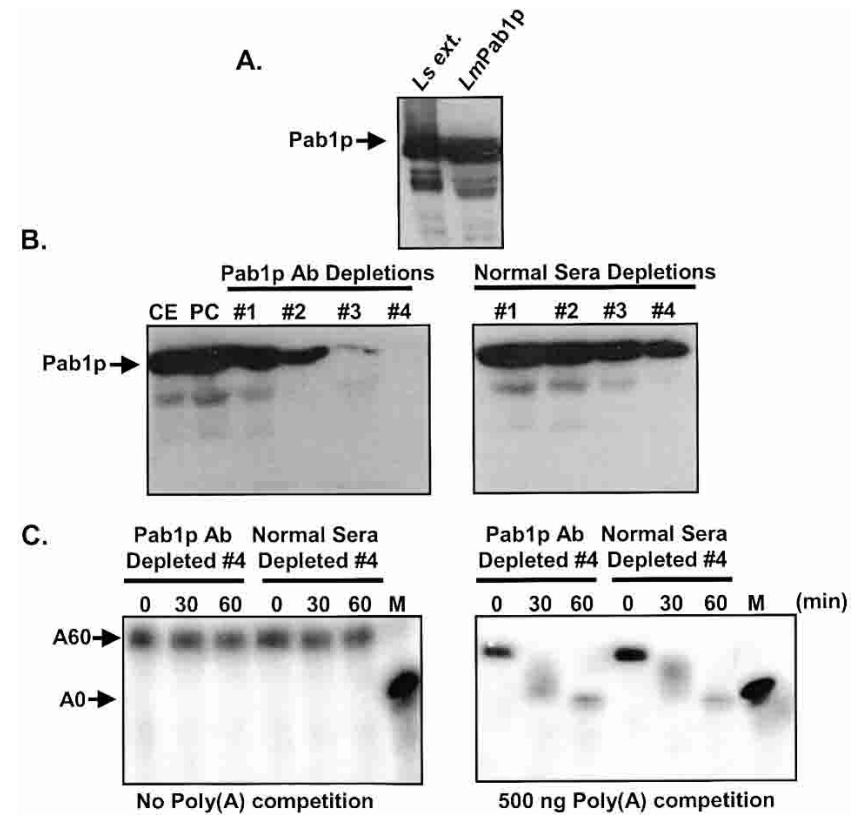

FIGURE 5. Pablp is not the only inhibitor of deadenylation in trypanosomal extracts. (A) Western blot analysis of L. seymouri cytoplasmic extract ( $L s$ ext.) and purified recombinant L. major Pablp (LmPablp) using a rabbit polyclonal antibody to L. major Pablp is shown. (B) Immunoprecipitation of Pablp from L. seymouri extracts was determined by analysis of the depleted extract using Western blots. Four rounds of immunoprecipitation were performed using $L m P a b 1$ antisera or rabbit normal sera. Cytoplasmic extract (CE) and precleared cytoplasmic extracts (PC) are indicated. Binding of the Pablp to the antibody-bead complex was confirmed by Western blotting (data not shown). (C) Fourth-round Pablp and normal seradepleted extracts were tested for deadenylation activity using SL-MCS A60 (169 nt) RNA substrate. Parallel 60-min reactions using either treated extract are shown with or without the addition of poly(A) homopolymer. The lanes labeled $M$ indicate SL-MCS A0 RNA (109 nt) as a marker. tails and exhibits a slowed deadenylase activity in vivo (Caponigro and Parker 1995). Because of these seemingly contradictory roles for Pablp in mRNA stability, we studied the function of Pablp using the trypanosome in vitro turnover system. Removal of Pablp from trypanosome extracts did not affect the rate of mRNA deadenylation or abrogate the requirement for poly(A) homopolymer addition. Furthermore, add-back experiments with recombinant Pablp restored stability to polyadenylated RNA in an extract that was depleted of poly(A)-binding activities. These results suggest that Pablp has an inhibitory function in trypanosome extracts.

Deadenylation is initiated in most in vitro mRNA turnover systems by addition of exogenous poly(A) homopolymer competitor to remove poly(A)-binding proteins (Ford et al. 1999; Wilusz et al. 2001a). This in vitro treatment generates a situation that does not reflect the in vivo way poly(A)-binding proteins are removed from the poly(A) tail. It is possible that in vivo, unidentified poly(A)-binding proteins serve not only to stabilize mRNA, but mediate removal of Pablp from the poly(A) tail. In trypanosomes, a limited number of proteins have been described that bind to poly(A) homopolymer. In the last few years, work has emerged from the Frasch group that has identified a class of RNA-binding proteins that interact with AU-rich elements in Trypanosoma cruzi (D'Orso et al. 2003). These six proteins, TcRBP1-TcRBP6, bind to RNA in a stage-specific fashion (D'Orso and Frasch 2001; De Gaudenzi et al. 2003). Most of these proteins have affinity for poly(U), but TcRBP3 also has affinity for poly(A) (De Gaudenzi et al. 2003). It is an intriguing possibility that these proteins may somehow mediate removal of poly(A)-binding proteins from the poly $(\mathrm{A})$ tail either alone or in concert with other tively, it is possible that a Pan2p-like deadenylase is present in the trypanosome extracts. Yeast Pan2p is dependent on Pablp (Brown et al. 1996; Brown and Sachs 1998). Therefore, we addressed the possibility of a Pan2p-like activity in our extracts by exploring a requirement for Pablp to modify the trypanosomal deadenylation activity. Furthermore, we utilized this system to examine the regulatory effects of Pablp as a deadenylase inhibitor. Pablp stimulates translation initiation, and stabilizes mRNA in the cytoplasm (Wilusz et al. 2001b). However, the role Pablp plays in mRNA turnover is not well defined. Although reports implicate Pablp in protecting RNA from deadenylation, a yeast pab1 $\Delta$ deletion strain accumulates mRNAs with long poly(A)

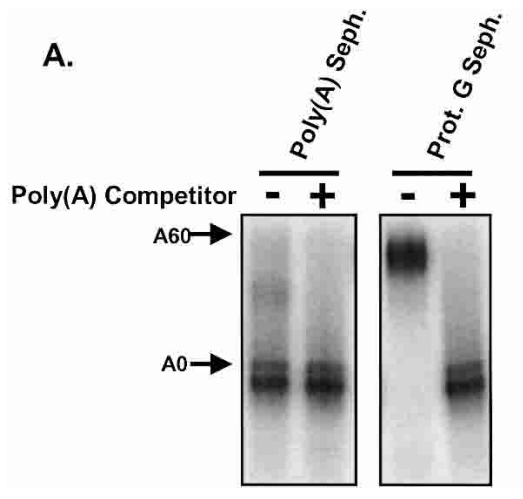

B.

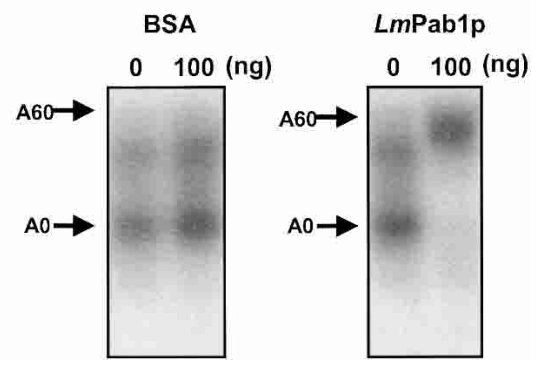

FIGURE 6. Pablp is an inhibitor of deadenylation in trypanosome extracts. (A) L. seymouri cytoplasmic extracts were incubated batch-wise with poly(A) Sepharose or Protein G Sepharose resin. The deadenylation activity of the supernatants were determined using Gem A60 RNA (125 nt) substrate with and without the addition of poly(A) homopolymer. (Left panel) The deadenylation activity of the treated extract from the poly(A) Sepharose incubation; (right panel) the deadenylase activity of the Protein G Sepharose-treated extract. (B) The poly(A)independent extract was incubated with $\sim 100 \mathrm{ng}$ of BSA (left panel) or purified recombinant $L m$ Pablp (right panel). Reaction products were separated using $7-\mathrm{M}$ urea $5 \%$ polyacrylamide gels. Arrows indicate the polyadenylated RNA substrate (A60) and the deadenylated substrate (A0) Gem A0 (65 nt). 
decay complexes such as the decapping proteins or the exosome. Another potential regulatory step may function through modification of Pablp. In trypanosomes as well as in higher eukaryotes, Pablp is phosphorylated (Bates et al. 2000). We do not know whether the anti-LmPablp antiserum cross-reacts with modified forms of L. seymouri Pablp, but it is possible that specific modified forms of Pablp remain in our extract and function to inhibit the deadenylation of the input substrate.

A summary of the major conclusions regarding proteinRNA interactions in trypanosome extracts is shown in Figure 7. (1) Polyadenylated RNAs are protected from $3^{\prime} \rightarrow 5^{\prime}$ degradation by RNA-binding proteins. These proteins stably associate with the poly $(\mathrm{A})$ tail and prevent access by the deadenylase. (2) Treatment of an extract by the addition of poly(A) homopolymer, or with poly(A) Sepharose, acts to remove all RNA-binding proteins from the poly(A) tail of the RNA. This allows the deadenylase to gain access to the RNA and degrade the poly(A) tail. (3) Addition of recombinant Pablp to a poly(A) Sepharose-depleted extract, devoid of poly(A)-binding proteins, prevents deadenylation. Therefore, Pablp has an independent inhibitory role in deadenylation. (4) Removal of Pablp from an extract does not remove all deadenylation inhibition. Other, as yet unidentified, poly (A)-binding proteins remain bound to the poly(A) tail and block deadenylation. Accordingly, we plan to further explore the role of Pap $1 \mathrm{~b}$ and other RNA-binding proteins in the regulation of trypanosomal deadenylation.
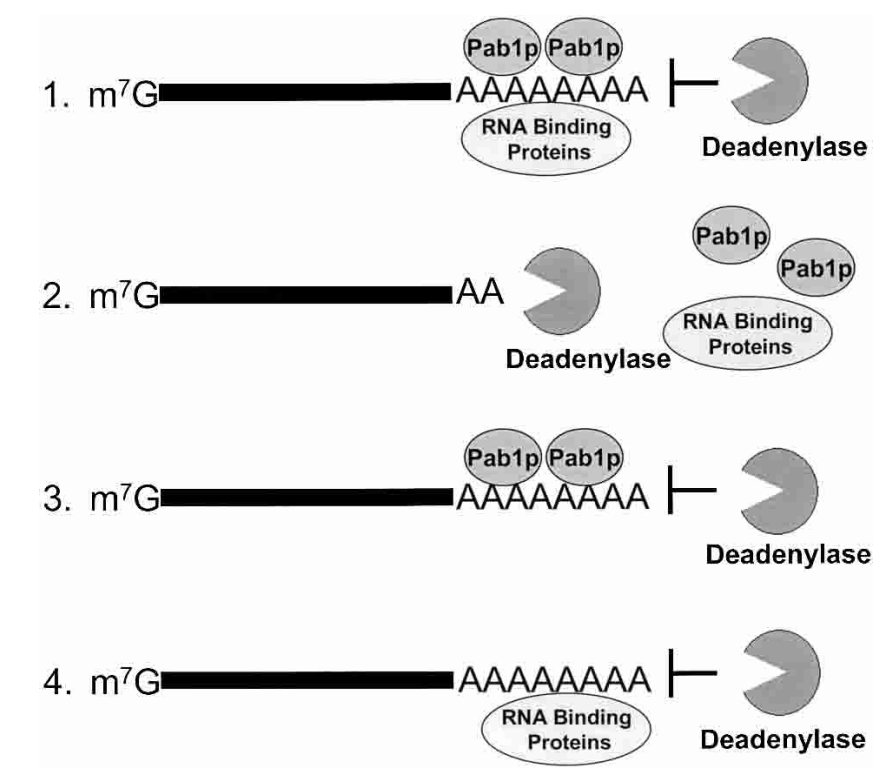

FIGURE 7. Deadenylation is triggered by removal of RNA-binding proteins that interact with the poly(A) tail. (1) mRNA is normally protected from deadenylation by RNA-binding proteins, including Pablp. (2) Addition of poly(A) homopolymer to extracts results in removal of poly(A)-binding proteins, including Pablp, allowing deadenylation of the poly(A) tail. (3) Addition of Pablp to unprotected poly(A) tails prevents deadenylation. (4) Removal of Pablp from extracts does not abrogate the requirement for poly(A) homopolymer addition to activate deadenylation.

\section{MATERIALS AND METHODS}

\section{RNA substrate preparation}

All RNA substrates were prepared as previously described (Ford and Wilusz 1999; Milone et al. 2002). Briefly, the DNA templates for SL-MCS A60, SL-MCS ARE A60, SL-MCS ERA A60, and Gem A60 RNAs were generated by digestion of the parent plasmids pSL-MCS, pSL-MCS ARE, pSL-MCS ERA, and pGem (Promega) with HindIII, followed by ligation to a DNA $A_{60}-T_{60}$ homopolymer with HindIII compatible ends. Recombinant PCR was performed using the ligated DNA as a template with two primers, M13 forward and JM37, that amplified the region containing the SP6 RNA polymerase promoter, plasmid multiple cloning site, and 60-bp A-T region. Following amplification, the PCR product was digested with SspI, phenol-chloroform extracted, and ethanol precipitated. MCS RNAs were produced using an initial recombinant PCR step to remove the L. seymouri SL-RNA sequence as previously described (Milone et al. 2002). SL-MCS ARE A60+20 and Gem A60+20 RNAs were prepared as described above, except that an SspI digestion was omitted. MCS A30-C9-A30 and Gem A30C9-A30 RNAs were prepared using a DNA template generated by substitution of the $A_{60}-T_{60}$ homopolymer described above with a homopolymer interrupted after the first $30 \mathrm{~A}-\mathrm{T}$ residues by a stretch of nine cytosine residues followed by the remaining $30 \mathrm{~A}-\mathrm{T}$ residues. These recombinant PCR-amplified A30-C9-A30 DNAs were digested with NsiI to generate poly(A) ends.

DNA templates were in vitro transcribed using SP6 RNA polymerase (New England Biolabs) with $\left[\alpha-{ }^{32} \mathrm{P}\right] \mathrm{UTP}$ for internal labeling or $\left[\alpha-{ }^{32} \mathrm{P}\right] \mathrm{GTP}$ for cap labeling. All RNAs are capped by inclusion of cap analog (Amersham) in the transcription reaction, unless noted. Uncapped RNAs were prepared by transcribing RNA in the absence of cap analog. Cap-labeled RNA was prepared as previously described (Milone et al. 2002). Following transcription, all RNAs were phenol-chloroform extracted, ethanol precipitated, and purified following separation using a $7 \mathrm{M}$ urea, $5 \%$ polyacrylamide gel. Gel-purified RNA was phenol-chloroform extracted twice, chloroform extracted once, and ethanol precipitated. Finally, the RNAs were resuspended in $\mathrm{ddH}_{2} \mathrm{O}$ and adjusted to $100,000 \mathrm{cpm} / \mu \mathrm{L}$ for use in assays. A0 makers were prepared as above by transcription of the pertinent linearized plasmid following HindIII digestion.

\section{Cytoplasmic extracts}

Leptomonas seymouri extracts were prepared as previously described (Milone et al. 2002). Trypanosoma brucei cytoplasmic extracts were similarly prepared. A total of $1 \mathrm{~L}$ of $T$. brucei strain 427 wild-type trypanosomes were grown to a density of $1-3 \times 10^{7}$ cells $/ \mathrm{mL}$ in two $1-\mathrm{L}$ flasks, gently shaking at $26^{\circ} \mathrm{C}$. Parasites were washed three times with PBS and resuspended in TbCE $(25 \mathrm{mM}$ HEPES at $\mathrm{pH} 7.2,100 \mathrm{mM} \mathrm{NaCl}, 10 \%$ glycerol, $0.1 \%$ triton $\mathrm{X}-100$, $1 \mathrm{mM}$ DTT, $1 \mu \mathrm{M}$ Pepstatin A, $1 \mu \mathrm{M}$ Leupeptin, and $1 \mathrm{mM}$ PMSF). Parasites were disrupted using a 21-guage needle and freeze-thaw lysed for several cycles (typically four to six cycles) in a dry-ice ethanol bath for $2 \mathrm{~min}$, and thawed at $42^{\circ} \mathrm{C}$ for $1 \mathrm{~min}$. Parasite lysis was ascertained through light-microscopy analysis of the suspension and the appearance of ghost cells. After lysis, the extract was precleared of debris by centrifugation $(11,500 \mathrm{~g}, 10$ 
$\left.\min , 4^{\circ} \mathrm{C}\right)$, and then centrifuged $\left(100,000 \mathrm{~g}, 1 \mathrm{~h}, 4^{\circ} \mathrm{C}\right)$ to generate the $\mathrm{S} 100$ fraction. The extract was aliquoted, quick-frozen, and stored at $-80^{\circ} \mathrm{C}$.

\section{Deadenylation assays}

Assay conditions were the same as used for decapping analysis (Milone et al. 2002). Briefly, an 11- $\mu \mathrm{L}$ reaction volume contained $50 \mathrm{mM}$ Tris- $\mathrm{HCl}$ (pH 7.9), $2.4 \mathrm{mM} \mathrm{MgCl}, 20 \mathrm{mM} \mathrm{KCl}, 30 \mathrm{mM}$ $\left(\mathrm{NH}_{4}\right)_{2} \mathrm{SO}_{4}, 4 \%$ glycerol, and $4 \mu \mathrm{L}$ of cytoplasmic extract (typically $40-80 \mu \mathrm{g}$ of total protein), and 10-50 fmole of RNA. Similarly, 4 $\mu \mathrm{L}$ of poly(A)/Protein G Sepharose-depleted or Pablp-immunodepleted extracts were also used per reaction. To activate deadenylation, $500 \mathrm{ng}$ of poly(A) homopolymer (Amersham) was added to the reaction unless otherwise stated. Poly $(\mathrm{C})$ homopolymer (Amersham) was used as a alternative competitor to poly $(\mathrm{A})$ for the indicated reactions. All reactions were preformed at $26^{\circ} \mathrm{C}$ for the indicated times, and reactions were terminated by addition of $300 \mu \mathrm{L}$ of $\mathrm{HSCB}(400 \mathrm{mM} \mathrm{NaCl}, 25 \mathrm{mM}$ Tris- $\mathrm{HCl}$ at $\mathrm{pH} 7.6,1 \%$ SDS, and $1 \mathrm{mM}$ EDTA). The terminated reaction products were phenol extracted, ethanol precipitated, and separated using $7 \mathrm{M}$ urea $5 \%$ polyacrylamide denaturing gels. Radioactive gels were exposed to PhosphorImager screens.

\section{Thin-layer chromatography analysis}

TLC analysis was largely performed as previously described (Martinez et al. 2001). Deadenylation reactions were performed as above and terminated by the addition of 25 mM EDTA. Reaction aliquots were increased to $20 \mu \mathrm{L}$, phenol-cholorform extracted, and $10 \mu \mathrm{L}$ of the aqueous phase spotted onto a BakerFlex PEI-F cellulose TLC plate (Baker). Nonradioactive 5'-AMP and 3'-AMP (Sigma) were added into the decapping reaction's aqueous phase prior to spotting as a marker. Plates were then washed for $20 \mathrm{~min}$ at room temperature in methanol, and air-dried. TLC plates were developed in $0.75 \mathrm{M} \mathrm{KH}_{2} \mathrm{PO}_{4}$ adjusted to $\mathrm{pH} 3.5$ with $\mathrm{H}_{3} \mathrm{PO}_{4}$. Following development, the plate was air dried and UV shadowed to visualize the $5^{\prime}$ and $3^{\prime}$-AMP markers. Deadenylation reaction products were visualized by exposure to a PhosphorImager screen.

\section{Pab1p analysis}

L. seymouri cytoplasmic extracts were treated with either poly(A) Sepharose (Amersham) or Protein G Sepharose (Amersham) in parallel to remove deadenylation inhibitory proteins. A total of $500 \mu \mathrm{L}$ of dry volume of Poly(A) or Protein G Sepharose resins were prepared by addition of $10 \mathrm{~mL}$ of PBS with protease inhibitors ( $1 \mu \mathrm{M}$ Pepstatin A, $1 \mu \mathrm{M}$ Leupeptin, and $1 \mathrm{mM}$ PMSF) and allowed to swell. The swelled resin was then washed three times with $10 \mathrm{~mL}$ volumes of PBS with protease inhibitors, and resuspended in $1 \mathrm{~mL}$ of PBS with protease inhibitors. A total of $100 \mu \mathrm{L}$ of resin slurry was washed with $1 \mathrm{~mL}$ of LsCE and used to deplete extract of deadenylase inhibitors. EDTA was added to $500 \mu \mathrm{L}$ of extract to a final concentration of $5 \mathrm{mM}$ to chelate any residual divalent cations. The extract volume was then equally split, and $250 \mu \mathrm{L}$ of extract incubated with $100 \mu \mathrm{L}$ of resin prepared above (30 min, rotating, $4^{\circ} \mathrm{C}$ ). Following incubation, the extract was cleared of the resin by centrifugation $\left(2000 \mathrm{~g}, 2 \mathrm{~min}, 4^{\circ} \mathrm{C}\right)$ and the supernatant removed. A small aliquot of the depleted extract was saved $(\sim 50 \mu \mathrm{L})$ and the remaining amount incubated with resin for a second round of depletion performed as above. The poly(A)/ Protein G Sepharose batch-purified fractions were quick-frozen and stored at $-80^{\circ} \mathrm{C}$.

A Protein A Sepharose suspension was prepared as described above for Protein G Sepharose. A total of $50 \mu \mathrm{L}$ of resin slurry was added to $25 \mu \mathrm{L}$ of rabbit polyclonal anti-LmPablp antisera or rabbit normal sera and incubated with Protein A for 40 min while rotating at $4^{\circ} \mathrm{C}$ (Bates et al. 2000). These antibody/Protein A/resin complexes were washed three times with $500 \mu \mathrm{L}$ of LsCE. A total of $300 \mu \mathrm{L}$ of $L$. seymouri cytoplasmic extracts were precleared by incubation $\left(40 \mathrm{~min}\right.$, rotating, $4^{\circ} \mathrm{C}$ ) with purified rabbit IgG and 50 $\mu \mathrm{L}$ of washed protein A resin slurry. Following incubation, the extract was cleared by a short spin $\left(2000 \mathrm{~g}, 2 \mathrm{~min}, 4^{\circ} \mathrm{C}\right)$ and the supernatant removed. A total of $40 \mu \mathrm{L}$ of precleared extract was removed for analysis, and the remaining extract was divided into equal portions. Each $130-\mu \mathrm{L}$ portion was added to the anti Pablp sera or normal sera-bound beads prepared above and incubated for $30 \mathrm{~min}$. The extract was cleared of the beads as above, and 20 $\mu \mathrm{L}$ of depleted extract saved. Four separate rounds of depletion were done, leaving $\sim 50-60 \mu \mathrm{L}$ of depleted extracts. Depleted extracts were quick frozen and stored at $-80^{\circ} \mathrm{C}$.

Purified recombinant L. major Pablp was prepared using the constructs and procedure as described (Bates et al. 2000). Purified His $_{6}$-tagged $L m$ Pablp was quantified by Bradford (Pierce) or by visual inspection on an $8 \%$ SDS-polyacrylamide gel and compared with BSA standards.

Western analysis was performed as described (Harlow and Lane 1988). A total of $4 \mu \mathrm{L}$ of $L$ seymouri total cytoplasmic extracts or depleted extracts were separated using an $8 \%$ SDS-polyacrylamide gel. Protein was transferred to PVDF membrane and blocked in blocking solution (5\% nonfat dry milk in PBS) for $1 \mathrm{~h}$ at room temperature. The membranes were blotted with a 1:1000 dilution of rabbit anti-LmPablp antisera in blocking solution for $1 \mathrm{~h}$ at room temperature, followed by three washes in PBS $0.1 \%$ Tween for $10 \mathrm{~min}$ each. Pablp antibody complexes were detected using an anti-rabbit IgG alkaline phosphatase conjugated antibody and detection reagents (Amersham). Briefly, a 1:10,000 dilution was made of secondary antibody in blocking solution and allowed to incubate with blot for $1 \mathrm{~h}$ at room temperature. The blot was washed as above, and development solution was added. Blots were visualized by exposure to film.

\section{ACKNOWLEDGMENTS}

We thank Elizabeth Bates and Deborah Smith for the His-tagged LmPAB1p construct and LmPablp antibodies. V.B. is supported by the National Institutes of Health grant AI29478, and an American Heart Association grant-in-aid. J.W. is supported by the National Institutes of Health grants GM63832 and CA80062.

The publication costs of this article were defrayed in part by payment of page charges. This article must therefore be hereby marked "advertisement" in accordance with 18 USC section 1734 solely to indicate this fact.

Received September 10, 2003; revised version accepted November 14, 2003. 


\section{REFERENCES}

Astrom, J., Astrom, A., and Virtanen, A. 1992. Properties of a HeLa cell 3' exonuclease specific for degrading poly(A) tails of mammalian mRNA. J. Biol. Chem. 267: 18154-18159.

Bates, E.J., Knuepfer, E., and Smith, D.F. 2000. Poly(A)-binding protein I of Leishmania: functional analysis and localisation in trypanosomatid parasites. Nucleic Acids Res. 28: 1211-1220.

Brown, C.E. and Sachs, A.B. 1998. Poly(A) tail length control in Saccharomyces cerevisiae occurs by message-specific deadenylation. Mol. Cell. Biol. 18: 6548-6559.

Brown, C.E., Tarun Jr., S.Z., Boeck, R., and Sachs, A.B. 1996. PAN3 encodes a subunit of the Pablp-dependent poly(A) nuclease in Saccharomyces cerevisiae. Mol. Cell. Biol. 16: 5744-5753.

Butler, J.S. 2002. The yin and yang of the exosome. Trends Cell. Biol. 12: $90-96$.

Caponigro, G. and Parker, R. 1995. Multiple functions for the poly(A)-binding protein in mRNA decapping and deadenylation in yeast. Genes \& Dev. 9: 2421-2432.

Chen, C.Y., Gherzi, R., Ong, S.E., Chan, E.L., Raijmakers, R., Pruijn, G.J., Stoecklin, G., Moroni, C., Mann, M., and Karin, M. 2001. AU binding proteins recruit the exosome to degrade ARE-containing mRNAs. Cell 107: 451-464.

Chen, J., Chiang, Y.C., and Denis, C.L. 2002. CCR4, a 3'-5' poly(A) RNA and ssDNA exonuclease, is the catalytic component of the cytoplasmic deadenylase. EMBO J. 21: 1414-1426.

Clayton, C.E. 2002. Life without transcriptional control? From fly to man and back again. EMBO J. 21: 1881-1888.

Daugeron, M.C, Mauxion, F., and Seraphin, B. 2001. The yeast POP2 gene encodes a nuclease involved in mRNA deadenylation. Nucleic Acids Res. 29: 2448-2455.

De Gaudenzi, J.G., D’Orso, I., and Frasch, A.C. 2003. RNA recognition motif-type RNA-binding proteins in Trypanosoma cruzi form a family involved in the interaction with specific transcripts in vivo. J. Biol. Chem 278: 18884-18894.

Dehlin, E., Wormington, M., Korner, C.G., and Wahle, E. 2000. Capdependent deadenylation of mRNA. EMBO J. 19: 1079-1086.

Di Noia, J.M., D’Orso, I., Sanchez, D.O., and Frasch, A.C. 2000. AUrich elements in the $3^{\prime}$-untranslated region of a new mucin-type gene family of Trypanosoma cruzi confers mRNA instability and modulates translation efficiency. J. Biol. Chem. 275: 10218-10227.

Dlakic, M. 2000. Functionally unrelated signaling proteins contain a fold similar to $\mathrm{Mg} 2+$-dependent endonucleases. Trends Biochem. Sci. 25: 272-273.

D'Orso, I. and Frasch, A.C. 2001. TcUBP-1, a developmentally regulated U-rich RNA-binding protein involved in selective mRNA destabilization in Trypanosomes. J. Biol. Chem. 276: 34801-34809.

D’Orso, I., De Gaudenzi, J.G., and Frasch, A.C. 2003. RNA-binding proteins and mRNA turnover in trypanosomes. Trends Parasitol. 19: $151-155$.

Drozdz, M. and Clayton, C. 1999. Structure of a regulatory $3^{\prime}$ untranslated region from Trypanosoma brucei. RNA 5: 1632-1644.

Estevez, A.M., Kempf, T., and Clayton, C. 2001. The exosome of Trypanosoma brucei. EMBO J. 20: 3831-3839.

Estevez, A.M., Lehner, B., Sanderson, C.M., Ruppert, T., and Clayton, C. 2003. The roles of inter-subunit interactions in exosome stability. J. Biol. Chem. 278: 34943-34951.

Ford, L.P. and Wilusz, J. 1999. An in vitro system using HeLa cytoplasmic extracts that reproduces regulated mRNA stability. Methods 17: 21-27.

Ford, L.P., Bagga, P.S., and Wilusz, J. 1997. The poly(A) tail inhibits the assembly of a $3^{\prime}-$ to- $5^{\prime}$ exonuclease in an in vitro RNA stability system. Mol. Cell. Biol. 17: 398-406.

Ford, L.P., Watson, J., Keene, J.D., and Wilusz, J. 1999. ELAV proteins stabilize deadenylated intermediates in a novel in vitro mRNA deadenylation/degradation system. Genes \& Dev. 13: 188-201.

Gao, M., Fritz, D.T., Ford, L.P., and Wilusz, J. 2000. Interaction between a poly(A)-specific ribonuclease and the $5^{\prime}$ cap influences mRNA deadenylation rates in vitro. Mol. Cell 5: 479-488.
Harlow, E. and Lane, D. 1988. Antibodies: A laboratory manual. Cold Spring Harbor Laboratory, Cold Spring Harbor, NY.

Korner, C.G. and Wahle, E. 1997. Poly(A) tail shortening by a mammalian poly(A)-specific 3'-exoribonuclease. J. Biol. Chem. 272:1044810456.

Korner, C.G., Wormington, M., Muckenthaler, M., Schneider, S., Dehlin, E., and Wahle, E. 1998. The deadenylating nuclease (DAN) is involved in poly(A) tail removal during the meiotic maturation of Xenopus oocytes. EMBO J. 17: 5427-5437.

Lai, W.S., Kennington, E.A., and Blackshear, P.J. 2003. Tristetraprolin and its family members can promote the cell-free deadenylation of AU-rich element-containing mRNAs by poly(A) ribonuclease. Mol. Cell. Biol. 23: 3798-3812.

Martinez, J., Ren, Y.G., Nilsson, P., Ehrenberg, M., and Virtanen, A. 2001. The mRNA cap structure stimulates rate of poly(A) removal and amplifies processivity of degradation. J. Biol. Chem. 276: 27923-27929.

Milone, J., Wilusz, J., and Bellofatto, V. 2002. Identification of mRNA decapping activities and an ARE-regulated $3^{\prime}$ to $5^{\prime}$ exonuclease activity in trypanosome extracts. Nucleic Acids Res. 30: 4040-4050.

Mitchell, P. and Tollervey, D. 2001. mRNA turnover. Curr. Opin. Cell. Biol. 13: 320-325.

Mukherjee, D., Gao, M., O’Connor, J.P., Raijmakers, R., Pruijn, G., Lutz, C.S., and Wilusz, J. 2002. The mammalian exosome mediates the efficient degradation of mRNAs that contain AU-rich elements. EMBO J. 21: 165-174.

Nuss, D.L., Furuichi, Y., Koch, G., and Shatkin, A.J. 1975. Detection in HeLa cell extracts of a 7-methyl guanosine specific enzyme activity that cleaves m7GpppNm. Cell 6: 21-27.

Quijada, L., Guerra-Giraldez, C., Drozdz, M., Hartmann, C., Irmer, H., Ben-Dov, C., Cristodero, M., Ding, M., and Clayton C. 2002. Expression of the human RNA-binding protein HuR in Trypanosoma brucei increases the abundance of mRNAs containing AUrich regulatory elements. Nucleic Acids Res. 30: 4414-4424.

Ren, Y.G., Martinez, J., Kirsebom, L.A., and Virtanen, A. 2002. Inhibition of Klenow DNA polymerase and poly(A)-specific ribonuclease by aminoglycosides. RNA 8: 1393-1400.

Ross, J. 1995. mRNA stability in mammalian cells. Microbiol. Rev. 59: 423-450.

Tucker, M. and Parker, R. 2000. Mechanisms and control of mRNA decapping in Saccharomyces cerevisiae. Annu. Rev. Biochem. 69: 571-595.

Tucker, M., Valencia-Sanchez, M.A., Staples, R.R., Chen, J., Denis, C.L., and Parker, R. 2001. The transcription factor associated Ccr4 and Cafl proteins are components of the major cytoplasmic mRNA deadenylase in Saccharomyces cerevisiae. Cell 104: 377-386.

Tucker, M., Staples, R.R., Valencia-Sanchez, M.A., Muhlrad, D., and Parker, R. 2002. Ccr4p is the catalytic subunit of a Ccr4p/Pop2p/ Notp mRNA deadenylase complex in Saccharomyces cerevisiae. EMBO J. 21: 1427-1436.

van Hoof, A. and Parker, R. 2002. Messenger RNA degradation: Beginning at the end. Curr. Biol. 12: R285-R287.

Vanhamme, L. and Pays, E. 1995. Control of gene expression in Trypanosomes. Microbiol. Rev. 59: 223-240.

Wang, Z. and Kiledjian, M. 2001. Functional link between the mammalian exosome and mRNA decapping. Cell 107: 751-762.

Wang, Z., Day, N., Trifillis, P., and Kiledjian, M. 1999. An mRNA stability complex functions with poly(A)-binding protein to stabilize mRNA in vitro. Mol. Cell. Biol. 19: 4552-4560.

Wells, S.E., Hillner, P.E., Vale, R.D., and Sachs, A.B. 1998. Circularization of mRNA by eukaryotic translation initiation factors. Mol. Cell 2: 135-140.

Wilusz, C.J., Gao, M., Jones, C.L., Wilusz, J., and Peltz, S.W. 2001a. Poly(A)-binding proteins regulate both mRNA deadenylation and decapping in yeast cytoplasmic extracts. RNA 7: 1-9.

Wilusz, C.J., Wormington, M., and Peltz, S.W. 2001b. The cap-to-tail guide to mRNA turnover. Nat. Rev. Mol. Cell. Biol. 2: 237-246.

Zuo, Y. and Deutscher, M.P. 2001. Exoribonuclease superfamilies: Structural analysis and phylogenetic distribution. Nucleic Acids Res. 29: 1017-1026. 

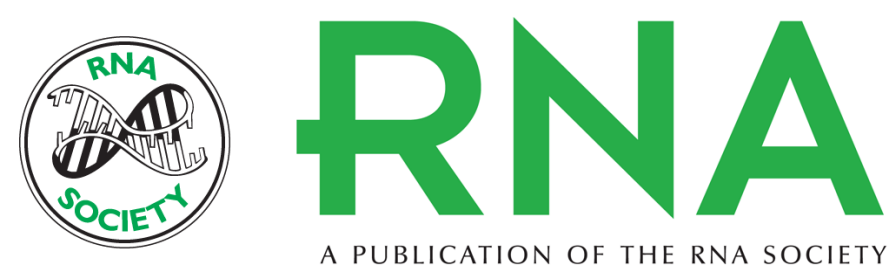

\section{Characterization of deadenylation in trypanosome extracts and its inhibition by poly(A)-binding protein Pab1p}

JOSEPH MILONE, JEFFREY WILUSZ and VIVIAN BELLOFATTO

RNA 2004 10: 448-457

References This article cites 45 articles, 25 of which can be accessed free at:

http://rnajournal.cshlp.org/content/10/3/448.full.html\#ref-list-1

\section{License}

Email Alerting Receive free email alerts when new articles cite this article - sign up in the box at the Service top right corner of the article or click here. 